\title{
DESIGNING URBAN BUILDING BLOCKS AROUND SOLAR PLANNING PRINCIPLES
}

\author{
ANDREAS SAVVIDES \& CONSTANTINOS VASSILIADES \\ Department of Architecture, College of Engineering, University of Cyprus, Cyprus
}

\begin{abstract}
This paper aims to determine the optimum geometry of the building blocks in order to ensure the viability of specific building integrated solar systems (BISTS, BIPV) in the current urban fabric. The research starts with an analysis of the fabric's geometry and characteristics as they are defined by law, and through a literature review, explores the possibilities of building integration of active solar systems in the urban fabric, whilst similar attempts of research are reported and analyzed. For the main body of the research, a simple set of rectangular building blocks is created, and through the configuration of some parameters the most viable geometry is determined, in order to have the most possible insolation on the buildings' roofs and facades. The parameters are the ratio between the length and the width of the building blocks, the width of the streets between them, the height of the buildings and the geometry of the buildings that can be accommodated in the proposed building blocks. The buildings' geometries are determined in ways that they could accommodate apartments in a viable way in order to create sustainable neighborhoods. The insolation, which reflects the potential for the building integration of active solar systems, is calculated with the use of digital modelling. The ultimate aim of this work is to present and analyze the limitations and problems of the integration in the urban fabric, and propose research-based solutions, which could establish a guide that gives guidelines for building integration of active solar systems on a neighborhood level. Further research will determine the ratio of the building's usable area/solar system's area if the geometry of the building is optimal, and the findings will be applied to the actual urban web of Cyprus in order to be optimized. It will also be investigated whether the solar urban design reduces the ability of the existing or potentially existing urban fabric to cover the needs of the city into residential units.
\end{abstract}

Keywords: solar planning, urban design, building massing, building insolation, sustainable development.

\section{INTRODUCTION AND LITERATURE REVIEW}

As more people choose to live in cities - European cities are home to nearly $80 \%$ of the population, resulting in the production of $75 \%$ of all $\mathrm{CO}_{2}$ emissions - one needs to look carefully at the urban morphology and its effect on energy consumption and climate change. According to Kanters and Horvat [1], savings in energy costs of $20-50 \%$ are possible through integrated planning and the careful consideration of site orientation and passive bioclimatic design strategies.

They note that utilization of solar radiation in urban areas appears to be essential and a practicable strategy, more so when one considers that in Europe by the end of 2020, all newly constructed buildings need to consume 'nearly zero energy' and that their needed energy needs to be produced locally as much as possible and with renewable sources. Consequently, being able to understand the solar potential is very important for architectural and urban designers when they integrate solar activated systems. When the integration of active solar technologies is taken into account early in the design process, it is more likely to lead to more holistically considered architectural and urban design proposals.

The authors note that the early integration might be made easier when architects are aware of locations where most energy can be produced and this may also be an important consideration for real estate developers, who can directly see the amount of energy which can be produced on site by roof and building envelope integrated systems. Consequently, 
design guidelines need to be developed that may be derived from parametric simulations that analyze building massing configurations and their potential contribution to locally produced energy and heat.

According to Hachem et al. [2], a number of parameters are considered in planning solar urban design for exploitation of solar radiation for lighting, heating and electricity generation and consequently neighborhoods may be designed to achieve net-zero energy consumption by addressing key parameters such as building shapes, density within a site and site layout.

Building shape plays a role in governing energy consumption in buildings and can provide advantages in capturing solar energy. In terms of solar planning, two main building surfaces, south facing roofs and facades, should be optimized for solar radiation. These surfaces serve as the basis for the placement and orientation of BIST panels and they may be configured to optimize solar energy utilization.

Moreover, according to the authors, the spatial characteristics of neighborhoods and land use regulations can significantly affect solar potential and energy demand of buildings and the orientation of a building and its position with respect to adjacent buildings determines its access to solar radiation, which in turn governs energy transfer mechanisms.

Several studies have focused on investigating the distribution of solar radiation on different surfaces in the built environment and its optimization, at the urban scale. Still, the interest in the effect of urban development on solar energy access and the interaction between individual shapes, their density within a site and the site layout may be discussed even further.

This work was preceded by a study of the effect of key design parameters on energy performance of two story single family dwellings and small scale neighborhoods, in a mid-latitude northern climate [3]. The effects of the design parameters were presented in a matrix that related design parameters to performance criteria and performance criteria considered were heating and cooling energy consumptions and solar energy generation.

In two other papers from 2011 by the same team of investigators, parametric investigation is used to examine how geometric form effects on solar potential of housing units and also the solar potential of housing units in different neighborhood designs [4], [5]. In the first instance, the study investigates the effect of these shapes on two major response variables - Solar radiation incident on equatorial-facing facades and transmitted by the fenestration of such facades, and electricity production potential of building integrated photovoltaic (BIPV) covering roof surfaces with optimal solar exposure.

In the second instance, the authors present a methodology for investigating the influence of three major parameters in the design of two-story housing units in different neighborhood layouts, on solar energy utilization potential. The parameters are geometric shapes of individual units, density of units and site layouts. The density parameter is represented by detached and multiplexed units and the simulation configurations consist of combinations of the parameter values, followed by an evaluation of the change from reference configurations of the response parameters.

The work of Van Esch et al. [6], also looks at the effects of urban and building design parameters on solar access, but taking also into consideration the space between the building masses that forms a sort of urban canyon and looks at the potential for direct passive solar heating strategies. They note that the urban climate influences the climatic performance and needs of buildings and the ways in which the city's outdoor spaces are being used. On account of these differences, outdoor spaces between building masses may provide both areas of sun and shade for user occupation according to what makes them feel comfortable.

In an urban setting, solar radiation collection is constrained by street layouts and the shape of neighboring buildings. Obstructions put restrictions on building skins and on the potential of solar radiation to contribute to lowering the heat demand or to obstruct solar radiation, 
leaving surrounding outdoor spaces partly or completely in shade. The authors' research looks at configurations of urban canyons that benefit both outdoor and indoor solar conditions; providing as much solar irradiation in colder seasons and shade in warmer seasons and it does so by analyzing the influence of different urban and architectural parameters: the orientation of streets and facades and the design and shapes of roofs and building envelopes.

Compagnon [7], also pursued a method to quantify the potential of facades and roofs located in urban areas for active and passive solar heating, photovoltaic electricity production and daylighting. He considered solar irradiation and illuminance values obtained through numerical simulations to form the core of the methodology, centered on a case study comparing different building layouts at constant density in Fribourg, Switzerland.

In their work on cities, Sanaieian et al. [8], review the impact of urban block form on thermal performance, solar access and ventilation. They look at form and position of urban blocks in the way in which they influence not only the micro-climate but also the energy performance potential for each block configuration. Their discussion of these parameters on the energy performance of the examined building blocks reviews existing methods and techniques to predict thermal behavior, solar access and ventilation on a neighborhood scale.

Stevanović [9] and Kämpf et al. [10], approach the optimization of passive solar design strategies and the buildings' solar irradiation availability from the point of view that passive solar design strategies comprise important ways of reducing the heating, cooling and lighting energy consumption of buildings. Their work constitutes a review of previous studies of simulation-based optimization of passive solar design strategies in order to improve the sustainability of new and existing urban settlements, given that it is desirable to maximize the utilization of the solar energy incident on the building envelope, whether by passive or active means. The parameters they examine are geometric, such as: the height of buildings up to their façade and the height and orientation of roofs, but with the constraint of maintaining an overall built volume.

Tian et al. [11], utilize the cell-to-module-to-array model to investigate the effects of temperature and shading on the performance of building integrated systems, while Evins [12], presents a comprehensive review of all significant research, applying computational optimization to sustainable building design problems. In both cases, key fields such as: envelope des ign, including constructions and form; configuration and control of building systems; renewable energy generation; and holistic optimizations of several areas simultaneously, with particular focus on residential and retrofit, were reviewed in detail.

A method to evaluate the adaptability of building integrated systems on urban façades was proposed by Esclapés et al.[13], proving that solar simulation and evaluation tools are essential for the design of novel energy and environmental strategies. Their research also presented a method, based on Geographic Information Systems (GIS), for defining the potential of solar energy and heat over urban façades, by generating 3D solar maps from standard data sources. These were then related to urban and solar geometries thus permitting the study of the optimal parameters for systems integration over façades, in a representative urban area of Madrid.

Smith and Levermore [14], and Aelenei and Gonçalves [15], examined the design of urban spaces and buildings respectively, to improve sustainability and quality of life in a warmer world. They showed that at the urban scale proven ways of doing this include altering the urban microclimate by modifying its heat absorption and emission, for example through urban greening, the use of high-reflectivity materials and by increasing openness to allow cooling winds, while at the building scale, improved comfort and higher levels of sustainability may be achieved by taking advantage of exemplary façade, glazing and ventilation designs. 
Lobaccaro et al. [16] and Frontini [17], in two recent papers, examined the optimization of solar façades in urban canopy layers and how urban densification affects existing buildings, respectively. In the first instance their research was aimed at assessing the amount of energy that can be produced by solar envelopes, through dynamic yearly analyses on a sample building, to identify the main parameters influencing the availability of solar radiation and to optimize the building's shape. In the second instance they focused on a new solar urban planning approach for building densification and preservation in existing urban areas.

In three papers from 2012-2014, Amado and Poggi [18]-[20], examined solar energy integration in urban planning by using the Geographical Urban Units Delimitation (GUUD) model. In an evolving methodology over this time their studies were based in part on a parametric approach to quantify solar energy potential from photovoltaic systems in the urban context. On this basis, they utilized a workflow that combined geographical information system $\left(\operatorname{ArcGIS}^{\circledR}\right)$, parametric modeling (Rhinoceros ${ }^{\circledR}-$ Grasshopper $^{\mathrm{TM}}$ ) and solar dynamic analysis $\left(\mathrm{Geco}^{\circledR}-\right.$ Ecotect $\left.^{\circledR}\right)$, to examine he performance of integrated systems in Oeiras, a medium-size city in Portugal.

Furthermore, they explored the concept of Solar Urban Planning with the goal of developing an operative methodology to achieve the best conditions towards Zero Energy Building (ZEB) to address a perceived transformation in the form of cities, from being relatively compact to a confused urban sprawl. They implemented what they called a new step in determining the solar potential of an urban area, by connecting the energy and heating needs of buildings and their capacity to achieve this through the integration of solar systems based on solar analysis with parametric urban design suggested as a useful tool to be added into the conception phase of urban planning.

Lastly, the works of both Spiegelhalter [21] and Tombazis and Preuss [22], dating from the start of the millennium, help wrap up this literature review by the noting the continued need for holistic architectural and urban design and planning concepts. The goal should be the design of solar sensitive buildings within given urban contexts, arranged freely so as to maximize access to natural resources. A comprehensive bioclimatic design in such a given urban environment must carefully investigate and assess access to natural resources while taking into account the negative influences that might prevail around the site. The associated constraints can be a challenging but very interesting and rewarding starting point for architectural design. If understood and considered from the beginning these constraints can lead to creative and innovative architectural and urban design proposals.

Regional scenario tools and eco-audit measures in an international context may then integrate social and ecological responsibilities for open-ended, multifunctional urban spaces and urban growth management. Within this emerging paradigm, governmental, university and community-wide programs and business leaders should target solar urban planning and building design, housing and working environments, walking and bicycling friendly streetscapes and attractive public transportation systems, as an important step to achieving sustainability for human settlements.

\section{DESIGN CRITERIA AND METHODOLOGY FOR INVESTIGATION}

In the discussion juxtaposing the twin goals of planning for higher densities and enabling insolation of southern facing roofs and facades, dense urban environments provide an opportunity to couple principles of compact city planning with solar availability and urban daylighting. One has to account, however, for the complex and dynamic overshadowing effects created by the building masses themselves [17]. Consequently, quantifying these effects may lead to optimization of building massing placement within an urban block and can significantly affect daylight and the thermal performance of buildings, as well as the 
potential for solar activated building integrated systems generating heat and electricity. It is therefore necessary to use simulation tools in order to examine alternative configurations for the physical layout of settlements and to act in accordance with European building regulations, which are anticipating the evolution of a Net Zero Energy City.

The research presented below proposes a design approach using modeling tools and dynamic simulation software, such as Revit Architecture and Ecotect by Autodesk, in order to examine optimal urban morphologies at the scale of building massing in typical urban blocks. In developing this, a key area of confusion according to Towers is the common association of 'high density' with 'high rise' [23]. This is partly an elementary word association. But it is also due to the continuing poor reputation of the multi-story social housing dating from the 1950s to the 1970s. Many of these comprised high-rise tower and slab blocks that were identified with a variety of functional and social problems. It would be a mistake, however, to identify these building forms with attempts at optimizing higher densities.

Consequently, in order to examine the potential of typical building configurations on an urban block against its optimization in terms of its density potential and solar collector potential, some design criteria based on a simple taxonomy of basic building typologies should be adopted. Such a taxonomy may be found from the works of Martin and March [24], who published a cogent analysis of the key forms of urban development. They postulated that on any given site development can take three basic forms which they called 'pavilion', 'street' and 'patio' (Fig. 1). These forms have different floor and land coverage ratios and according to the authors, if developed with buildings of the same height and depth, the pavilion form would provide the lowest density and the patio form the highest.

For the sake of this investigation in utilizing these three different typological layouts, the simulations propose to hold net floor areas constant for all configurations, so as to be able to compare the potential of insolation of southern facing roofs and facades based just on building massing forms and their configuration on the site. Therefore, keeping considerations of density constant, constructing a given amount of floor space would lead to building massing of varying heights depending on the typology they followed, which is also illustrated by Fig. 1 in the form of, e.g. a fifteen-story tower block, five-story linear blocks or a three-story perimeter block, which represent some of the most prevalent housing typologies encountered in contemporary metropolitan areas.

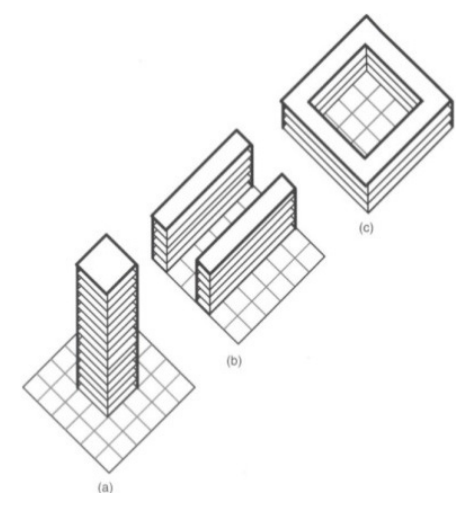

Figure 1: 'Pavillion' street' and 'patio' building archetypes by Martin and March [24]. 
According to Towers the pavilion corresponds to the detached housing configuration; the linear form to the traditional street layout of tenements; while the perimeter block takes the form of housing projects found in most urban areas, especially in continental Europe. In Britain, the Garden City movement promoters regarded terraced housing as leading to cramped and dark spaces, while higher-density traditional forms were objectionable to reformers because of the high proportion of land they covered [23]. Similarly, the proponents of the Modern Movement similarly objected to the layout of the continental urban blocks with their deep plans and dark internal courts. It is for those historical reasons that many of these basic building massing typologies were used as the basis for the design of the many multi-story buildings that have been occupying the urban fabric in the inter war years and post war period till today.

In those formative years, urban designers consciously sought housing types which would provide more light and air and which would release more of the ground as open space. Towers references the work of Le Corbusier who had envisioned cities as composed of huge tower blocks set in extended parks, as exemplified in his proposal for a "Ville Radieuse" and a plan for the redevelopment of a large area of central Paris (Fig. 2).

Similarly in Germany and later in the USA, Walter Gropius investigated linear blocks which were best orientated on an east/west axis, in parallel rows and with the long dimension of the blocks facing south, in a formation he named "Zielenbau" (Fig. 3) and whereby he calculated that eight-story slab blocks provided an appropriate distance from neighbors for privacy purposes, as well as optimal conditions of views to the landscape, fresh air and sun.

These tower and slab blocks did free up more open space, even though post occupancy evaluations showed that in many cases the space in between the building blocks was underutilized. Tall buildings, disassociated from public life and activities at ground level proved to be inappropriate for families with children, despite their earnest ambition to provide openness, light and air. The search for appropriate forms that lead to better solar planning for more compact cities should look for basic forms in massing configurations that lead to higher densities and prevalent and unobstructed southern exposures to the sun and away from single suburban houses and housing tower blocks that propagate urban sprawl.

Consequently, the research introduced herein presents an investigation of the effects of some basic design criteria that take into account the discussion above, addressing aspects of urban morphology with regards to aspects of density of habitation and building massing configuration that looks to optimization of insolation on southern exposed roofs and façades.

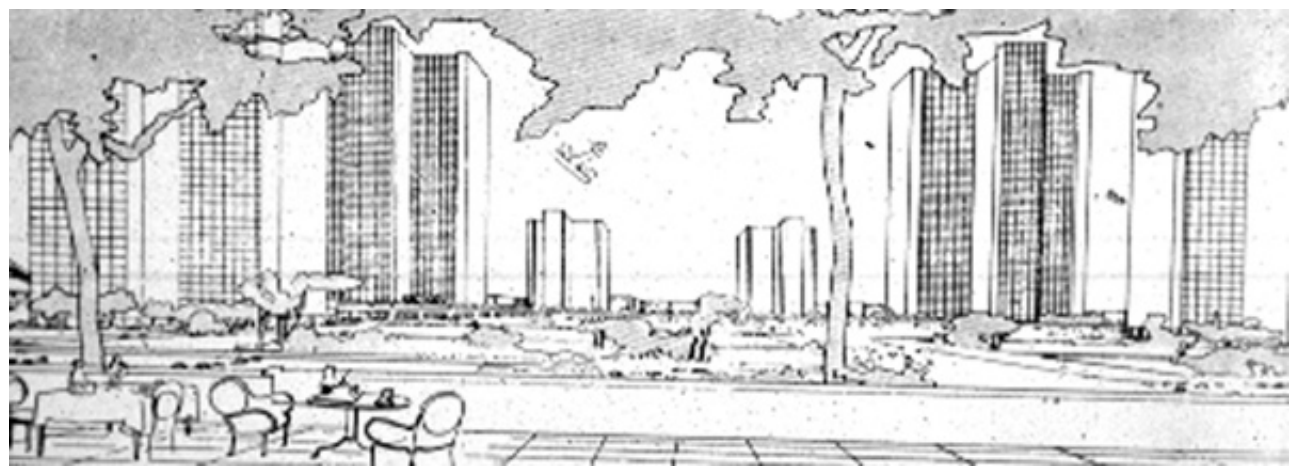

Figure 2: Excerpt from 'La Ville Radieuse' by Le Corbusier. 
(a)
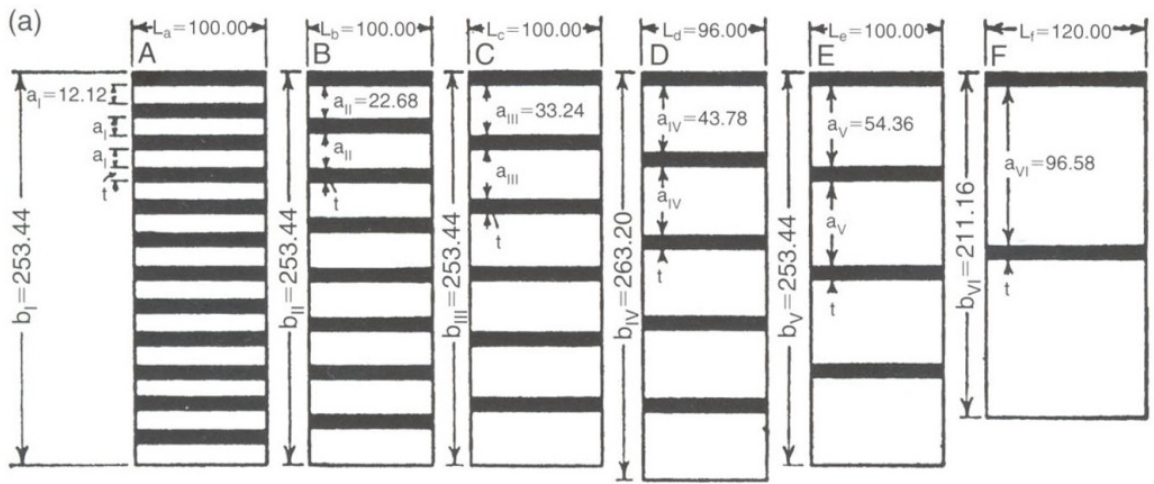

(b)

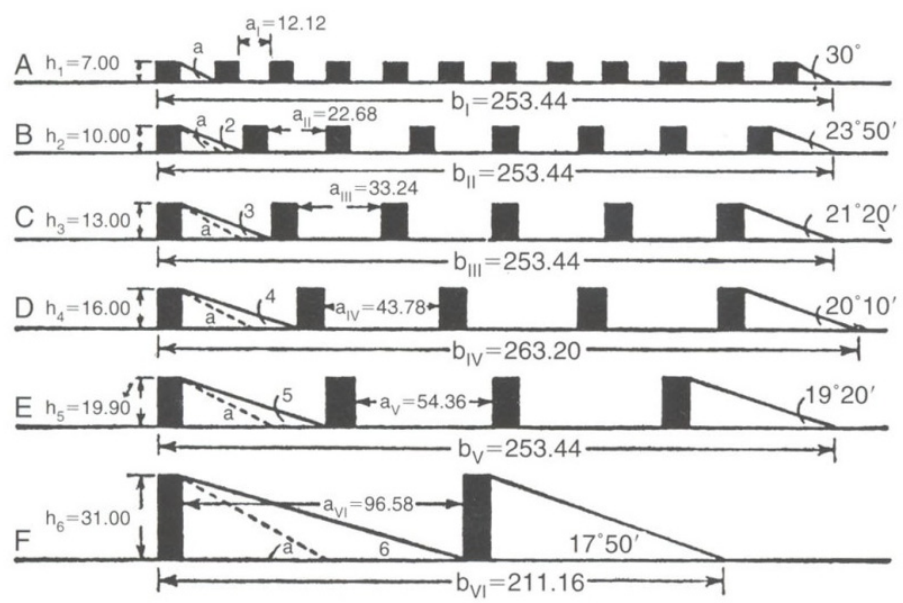

Figure 3: 'Zielenbau' housing block proposal by Walter Gropius.

Similarly to the setting of some basic simulation criteria as indicated by Hachem [4], and others whose work is mentioned in the literature review section above, some typical building massing configurations are utilized in this case as well. These design criteria include: the shape and orientation of individual units and the site layout. The solar potential includes the radiation incident on near south facing facades and the solar thermal potential afforded to BISTSs mounted in the near south facing roofs and facades.

For purposes of research, the venue for the investigation is a simplified hypothetical neighborhood unit of the Mediterranean island country of Cyprus and they conform to simplified urban design and zoning bylaws and guidelines such as those proposed by the Department of Town Planning and Housing and by the Department of Public Roads. Typical Land Coverage Ratios (up to 70\%) and Floor Area Ratios (up to 340\%), as well as building height $(19.8 \mathrm{~m})$ and floor number (6 fl.) restrictions follow those of typical suburban configurations and they are varied so as to keep density constant and to isolate the investigation towards the optimization of building massing configurations within the aforementioned neighborhood unit, as shown in Fig. 4. 

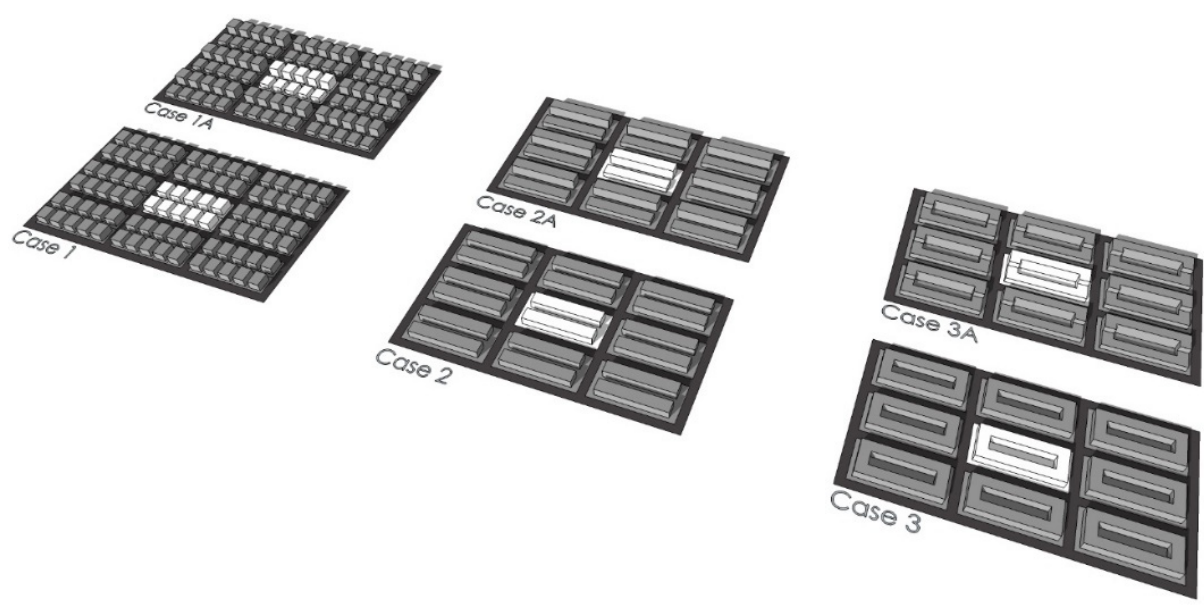

Figure 4: Parametric investigation of building massing keeping density constant.

More specifically, the general characteristics for the investigation are based on various local bylaws, though primarily on typical parameters indicated by local area plans, assuming a medium density, associated with a suburban area. As with other authors, the design methodology consists of first determining the site layout, second designing the unit shapes to conform to this layout and third combining the shapes in different configurations.

Each building block measures 5250 square meters in area, which is typical of Cyprus. Building setbacks from lot lines were: $3 \mathrm{~m}$ for the first three stories of the building mass; $4 \mathrm{~m}$ for the fourth floor of the building mass; and $5 \mathrm{~m}$ for each subsequent floor or at the discretion of the local planning authority. Road and sidewalk widths are dimensioned to measure: $12.8 \mathrm{~m}$ ( $7.4 \mathrm{~m}$ of road and $2.7 \mathrm{~m}$ of sidewalk; $11 \mathrm{~m}$ ( $7 \mathrm{~m}$ of road and $2 \mathrm{~m}$ of sidewalk); and $7.9 \mathrm{~m}(5.5 \mathrm{~m}$ of road and $1.2 \mathrm{~m}$ of sidewalk), respectively.

For each couple of these three different massing configurations based on the 'pavilion', 'street' and 'patio' archetypes the height of the buildings in the base case was kept at three stories high (typical for suburban Cyprus at $9.9 \mathrm{~m}$ ) while in each alternative 'a' case, each building was split in two masses with a two story component $(6.6 \mathrm{~m})$ to the south and a four story component $(13.2 \mathrm{~m})$ to the north. The dimensions and proportions of the massing configurations used are such that they may be rationally subdivided into functional apartment units per floor plate with minimum loss of usable area for vertical and horizontal circulation.

Building massing geometries were modelled in Revit Architecture ${ }^{\circledR}$ and Ecotect $^{\circledR}$ by Autodesk. In Ecotect ${ }^{\mathbb{B}}$, a solar access analysis was run using 'medium' settings, looking at the incident solar radiation over a whole year on the building envelope of the urban block, for the specific location (Fig. 5). The basic design of the units relies on passive solar design principles and local best practices and traditions [25]. The design ensures that the overall east-west dimension of the house - the solar façade, is larger than the perpendicular dimension (north-south), to maximize passive solar gains in winter. 

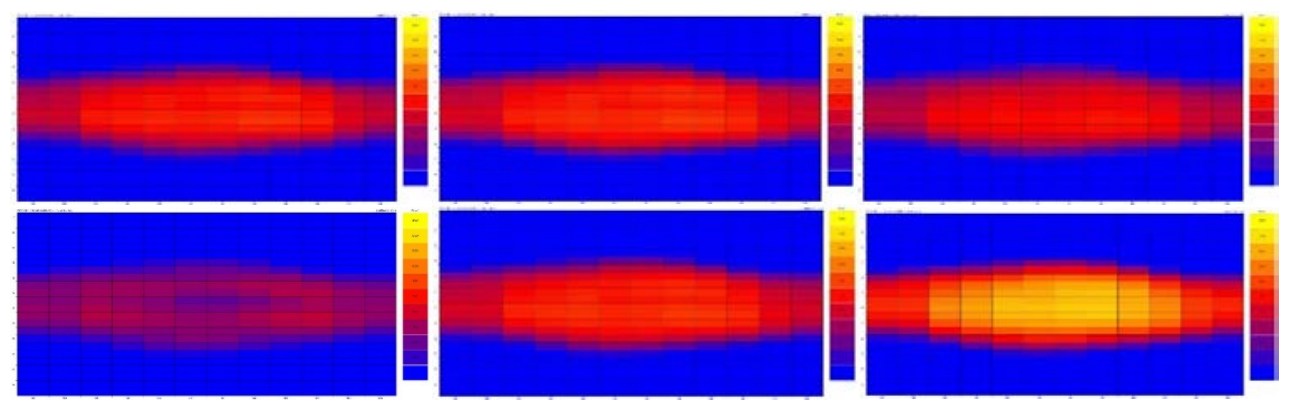

Figure 5: Incident solar radiation charts $\left(\mathrm{kwh} / \mathrm{m}^{2} / \mathrm{yr}\right)$ for alternative massing configurations.

The incident solar radiation was simulated annually, ensuring the issue of seasonal imbalance between energy and heat production and need was not taking into account here. Moreover, the integrated solar systems area was considered to be $75 \%$ of the façade area, leaving $25 \%$ for fenestration. The value of $25 \%$ for fenestration is appropriate for Mediterranean areas, since too much fenestration can lead to visual problems such as glare in the interiors of spaces, as well as unwanted overheating in the summer. The same ratio was chosen for the roof, since a certain portion of the roof surface is needed for building services equipment, skylights and building maintenance access ways.

\section{DISCUSSION OF RESULTS AND CONCLUSIONS}

Once the simulations were ran the solar exploitation results on southern facing roofs and façades keeping density of occupation constant were tabulated and then analyzed in terms of their performance in maximizing incident insolation. For each one of the case studies results were also plotted that examined the degree of correlation between: surface area of southern roofs and façades/total surface area of building envelope v. solar exposure; surface area of southern roofs and façades/usable building floor area v. solar exposure; and surface area of southern roofs and façades/total volume of building envelope v. solar exposure, as shown in Table 1 and Fig. 6.

Table 1: Tabulation of the solar exploitation results for the six case studies.

\begin{tabular}{|c|c|c|c|c|c|c|c|c|c|c|}
\hline & $\begin{array}{r}\text { Usable } \\
\text { Building } \\
\text { Area (m2) }\end{array}$ & $\begin{array}{r}\text { Exposed } \\
\text { Area } \\
(\mathrm{m} 2)\end{array}$ & $\begin{array}{r}\text { Volume } \\
\text { (m3) }\end{array}$ & $\begin{array}{r}\text { External } \\
\text { surface } \\
\text { area per } \\
\text { volume } \\
\end{array}$ & $\begin{array}{r}\text { Built surface } \\
\text { / Area } \\
\text { building } \\
\text { blocks } \\
\end{array}$ & $\begin{array}{r}\text { Area of South } \\
\text { Surfaces / } \\
\text { Usable } \\
\text { Building Area }\end{array}$ & $\begin{array}{r}\text { Area of South } \\
\text { Surfaces / } \\
\text { Exposed Area }\end{array}$ & $\begin{array}{r}\text { Available } \\
\text { Exposure } \\
(\mathrm{kWh} / \mathrm{m} 2 / \mathrm{yr})\end{array}$ & $\begin{array}{r}\text { Incident } \\
(\mathrm{kWh} / \mathrm{m} 2 / \mathrm{yr})\end{array}$ & $\begin{array}{r}\text { Percentage } \\
\text { of solar } \\
\text { exploitation }\end{array}$ \\
\hline Case 1 & 7560 & 9240 & 26460 & 0.35 & 1.51 & 0.19 & 0.16 & 2502.453 & 442.513 & 0.18 \\
\hline Case $1 \mathrm{~A}$ & 7560 & 9240 & 26460 & 0.35 & 1.51 & 0.19 & 0.16 & 2502.453 & 695.931 & 0.28 \\
\hline Case 2 & 7560 & 6678 & 26460 & 0.25 & 1.51 & 0.23 & 0.26 & 2502.453 & 760.552 & 0.30 \\
\hline Case 2A & 7560 & 6678 & 26460 & 0.25 & 1.51 & 0.23 & 0.26 & 2502.453 & 753.657 & 0.30 \\
\hline Case 3 & 7632 & 6996 & 26712 & 0.26 & 1.53 & 0.21 & 0.23 & 2502.453 & 1035.624 & 0.41 \\
\hline Case 3A & 7632 & 7164 & 26712 & 0.27 & 1.53 & 0.23 & 0.24 & 2502.453 & 636.862 & 0.25 \\
\hline
\end{tabular}



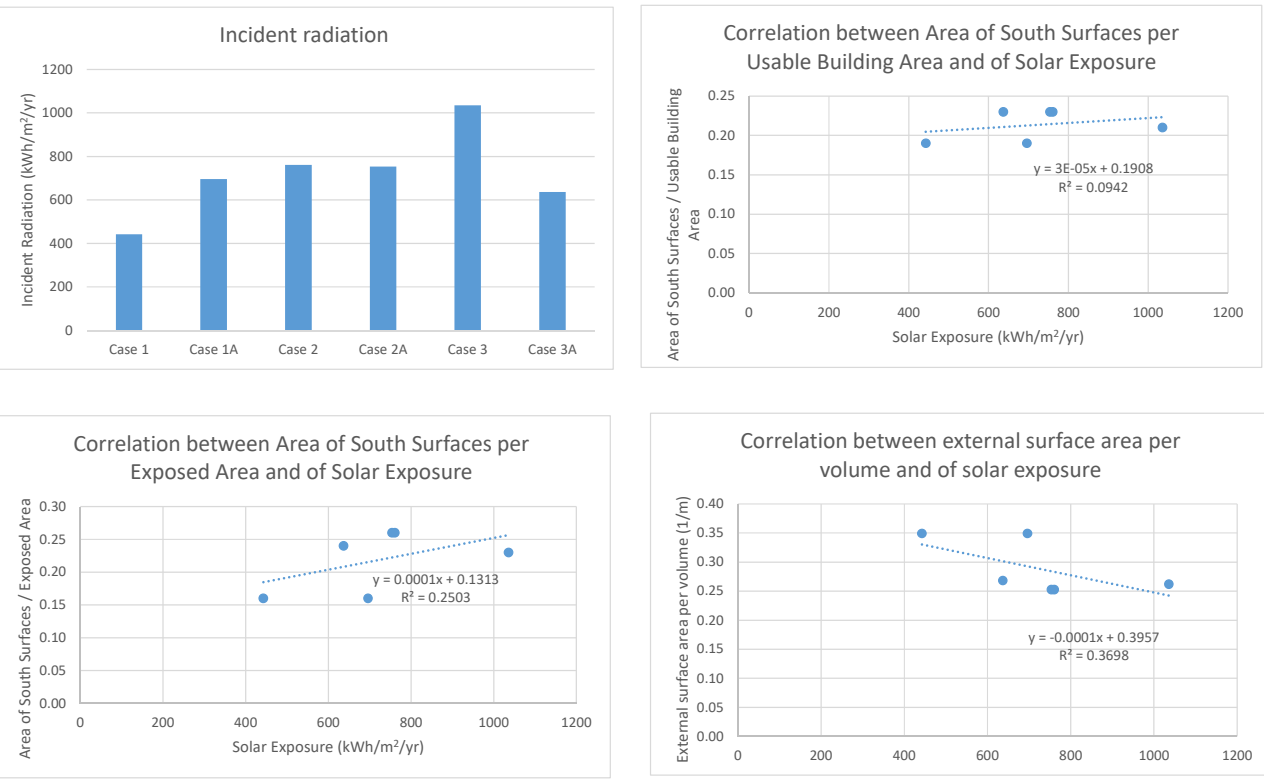

Figure 6: Insolation per case study and solar exposure correlations.

In terms of the ability of each case study to maximize and exploit incident radiation (insolation) upon southern facing roofs and façades, case study 3 that of the 'patio' configuration or perimeter block at a constant height of three stories seems to outperform the other alternatives scoring over $1000 \mathrm{kwh} / \mathrm{m}^{2} / \mathrm{yr}$, while the 'pavilion' or tower block configuration at a constant of three stories seems to have scored lowest at just over $400 \mathrm{kwh} / \mathrm{m}^{2} / \mathrm{yr}$. The third archetype, 'street' or horizontal block performs somewhere in the middle at just under $800 \mathrm{kwh} / \mathrm{m}^{2} / \mathrm{yr}$.

The results when plotted according to the metrics outlined above (always keeping density constant) indicate weak positive correlations in both surface area of southern roofs and façades/total surface area of building envelope v. solar exposure and also surface area of southern roofs and façades/usable building floor area v. solar exposure, while a weak negative correlation is noted in the case of surface area of southern roofs and façades/total volume of building envelope $\mathrm{v}$. solar exposure.

The results are by no means conclusive but they seem to indicate the need for designing not only individual buildings, but also agglomerations of buildings situated in city blocks and exhibiting a continuous street wall in southern facing orientations with proportionally greater surface area in southern facing roofs and façades v. other cardinal points. Furthermore, uninterrupted building masses with southern facing building roofs and façades that enclose proportionally smaller floor plates, potentially serve usable building floor area better. Contrarily, massing configurations that enclose proportionally more building volume per unit of southern facing roofs and façades are preferable.

Lastly, the results, though fairly inclusive support the building typology of 'patio' or perimeter block configuration to be found in continental Europe from Madrid to Warsaw and from Athens to Amsterdam, as long as these blocks exhibit to the greatest extent possible proportionately bigger areas of uninterrupted southern facing roofs and façades and also 
feature proportionately shallower floor plates from front to back of unit and have fairly higher floor to ceiling dimensions per unit.

\section{REFERENCES}

[1] Kanters, J. \& Horvat, M., Solar energy as a design parameter in urban planning. Energy Procedia, 30, pp. 1143-1152, 2012.

[2] Hachem, C., Fazio, P. \& Athienitis, A., Solar optimized residential neighborhoods: Evaluation and design methodology. Solar Energy, 95, pp. 42-64, 2013.

[3] Hachem, C., Athienitis, A. \& Fazio, P., Design methodology of solar neighborhoods. Energy Procedia, 30, pp. 1284-1293, 2012.

[4] Hachem, C., Athienitis, A. \& Fazio, P., Parametric investigation of geometric form effects on solar potential of housing units. Solar Energy, 85(9), pp. 1864-1877, 2011.

[5] Hachem, C., Athienitis, A. \& Fazio, P., Investigation of solar potential of housing units in different neighborhood designs. Energy and Buildings, 43(9), pp. 2262-2273, 2011.

[6] Van Esch, M.M.E., Looman, R.H.J. \& de Bruin-Hordijk, G.J., The effects of urban and building design parameters on solar access to the urban canyon and the potential for direct passive solar heating strategies. Energy and Buildings, 47, pp. 189-200, 2012.

[7] Compagnon, R., Solar and daylight availability in the urban fabric. Energy and buildings, 36(4), pp. 321-328, 2004.

[8] Sanaieian, H., Tenpierik, M., van den Linden, K., Seraj, F.M. \& Shemrani, S.M.M., Review of the impact of urban block form on thermal performance, solar access and ventilation. Renewable and Sustainable Energy Reviews, 38, pp. 551-560, 2014.

[9] Stevanovic, S., Optimization of passive solar design strategies: A review. Renewable and Sustainable Energy Reviews, 25, pp. 177-196, 2013.

[10] Kämpf, J.H., Montavon, M., Bunyesc, J., Bolliger, R. \& Robinson, D., Optimisation of buildings' solar irradiation availability. Solar energy, 84(4), pp. 596-603, 2010.

[11] Tian, H., Mancilla-David, F., Ellis, K., Muljadi, E. \& Jenkins, P., Determination of the optimal configuration for a photovoltaic array depending on the shading condition. Solar Energy, 95, pp. 1-12, 2013.

[12] Evins, R., A review of computational optimisation methods applied to sustainable building design. Renewable and Sustainable Energy Reviews, 22, pp. 230-245, 2013.

[13] Esclapés, J., Ferreiro, I., Piera, J. \& Teller, J., A method to evaluate the adaptability of photovoltaic energy on urban façades. Solar Energy, 105, pp. 414-427, 2014.

[14] Smith, C. \& Levermore, G., Designing urban spaces and buildings to improve sustainability and quality of life in a warmer world. Energy policy, 36(12), pp. 4558-4562, 2008.

[15] Aelenei, L. \& Gonçalves, H., From solar building design to net zero energy buildings: Performance insights of an office building. Energy Procedia, 48, pp. 1236-1243, 2014.

[16] Lobaccaro, G., Fiorito, F., Masera, G. \& Poli, T., District geometry simulation: a study for the optimization of solar façades in urban canopy layers. Energy Procedia, 30, pp.1163-1172, 2012.

[17] Lobaccaro, G. \& Frontini, F., Solar energy in urban environment: how urban densification affects existing buildings. Energy Procedia, 48, pp. 1559-1569, 2014.

[18] Amado, M. \& Poggi, F., Towards solar urban planning: A new step for better energy performance. Energy Procedia, 30, pp. 1261-1273, 2012.

[19] Amado, M. \& Poggi, F., Solar energy integration in urban planning: GUUD model. Energy Procedia, 50, pp. 277-284, 2014. 
[20] Amado, M. \& Poggi, F., Solar Urban Planning: a parametric approach. Energy Procedia, 48, pp. 1539-1548, 2014.

[21] Spiegelhalter, T., Towards zero $m$ energy urban areas suburban growth and environmental injustice in USA. Renewable Energy Focus. 2(5), pp. 22-24, 2001.

[22] Tombazis, A.N. \& Preuss, S.A., Design of passive solar buildings in urban areas. Solar Energy, 70(3), pp. 311-318, 2001.

[23] Towers, G., Introduction to Urban Housing Design. Routledge, 2013.

[24] Martin, L. \& March, L., Urban Space and Structures (No. 1). Cambridge University Press, 1972.

[25] Chiras, D.D., The Solar House: Passive Heating and Cooling. Chelsea Green Publishing, 2002. 